\title{
Slug Dynamics in a Nearly Horizontal Pipe Using Non-Invasive Measurement Techniques
}

\author{
M. I. Siddiqui ${ }^{1}$, S. Munir ${ }^{1}$, M. R. Heikal ${ }^{1,2}$, A. Rashid A. Aziz ${ }^{1} \&$ S. C. Dass ${ }^{1}$ \\ ${ }^{1}$ Universiti Teknologi PETRONAS, Bandar Seri Iskandar, Perak, Malaysia \\ ${ }^{2}$ School of Computing Engineering and Mathematics, University of Brighton, Lewes Road, Brighton, UK \\ Correspondence: M. I. Siddiqui, Fundamental and Applied Sciences Department, Universiti Teknologi \\ PETRONAS, Bandar Seri Iskandar, 31750 Tronoh, Perak, Malaysia. E-mail: siddiqi_ciit2003@yahoo.com
}

Received: December 15, 2014

Accepted: December 30, 2014

Online Published: June 22, 2015

doi:10.5539/mas.v9n9p50

URL: http://dx.doi.org/10.5539/mas.v9n9p50

\begin{abstract}
This paper examines the effect of gas and liquid superficial velocities on the dynamics of the slug flow in a nearly horizontal pipeline. Instead of the invasive measurements the experiments were conducted using non-invasive techniques to measure slug frequency and bubble length in the slug flows. A simultaneous PIV-LIF technique was employed to measure the instantaneous velocity of both liquid and gas phases simultaneously using two CCD cameras. Effect of gas superficial velocity on the instantaneous measurements were studied and analyzed.
\end{abstract}

Keywords: slug flow, slug frequency, liquid-gas flow, PIV-LIF

\section{Introduction}

To avoid the damage caused by severe slugging, the prediction of slug frequency is an important parameter of most experimental studies. Slug frequency is defined as an inverse of a slug period. Whereas, a slug period is the time that required for a slug unit to pass through the point of measurement. The first comprehensive experimental investigations on slug flow characteristics were performed by Hubbard (1965). The prediction of the slug frequency was of considerable importance for avoiding the damage caused by unexpected volume and fluctuations caused by slugging. An empirical correlation for prediction of horizontal slug frequency was given by (Gregory and Scott, 1969):

$$
f_{s}=0.226\left[\frac{V_{s l}}{g d}\left(\frac{19.7}{V_{m}}+V_{m}\right)\right]^{1.2}
$$

where $f_{s}$ is the slug frequency, $V_{s l}$ is the superficial liquid velocity, $V_{m}$ is the mixture velocity, $g$ is the gravity and $d$ the inner diameter of the pipe. Further, Zabras (2000) gave a new frequency model which included the inclination effects by reformulating Gregory's frequency model:

$$
f_{s}=0.226\left[\frac{V_{s l}}{g d}\left(\frac{19.7}{V_{m}}+V_{m}\right)\right]^{1.2}\left(0.836+2.75 \sin ^{0.25}(\theta)\right)
$$

where $\theta$ is the inclination. Several experimental studies have been carried out in order to understand the nature of forces caused by slug flow in pipelines (Sanchez et al., 1998) followed by (Tay and Thorpe, 2002). It is generally accepted that the short hydrodynamic slugs are the main cause of destructive forces in pipe bends and fittings (Tay and Thorpe, 2004). When the pipeline is operated at relatively low pressure and flow rates, long slugs may appear. Such long slugs can cause serious operational problems due to the strong fluctuations in flow supply and pressure, which may exceed the capacity of the downstream facilities, such as the separator or slug catcher, compressor, and heat exchanger (U. Kadri et al., 2011). Most of these studies have reported investigations into the formation mechanism of the slugs and the effect of physical properties on such mechanisms.

Since the slug flow phenomenon is stochastic in nature, thus the slug length distribution is not uniform along the pipe. In order to design the slug catchers and other downstream flow components the prediction of slug length more particularly the liquid slug length (slugy body length) is vital. The liquid slug length strongly depends upon 
the different flow configurations and the inlet conditions such as superficial velocities, pressure, diameter and inclination of the pipeline (Taitel, 1987).

Paglianti et al. (1996) measured the slug length in a $13 \mathrm{~m}$ long transparent pipe having $31.7 \mathrm{~mm}$ inner diameter for a wide range of superficial liquid velocities. He investigated the effect of the mixture Froude number, $F_{r_{m}}=\frac{V_{m}}{\sqrt{\mathrm{gd}}}$, on the slug length and noticed a significant increase in the length with increasing the mixture Froude number. Fabre et al. (1999) proposed a model to predict the shape and length of the gas bubble in a unit slug. He showed that the gas bubble length was a function of pipe diameter, liquid slug velocity, bubble volume and its velocity. Behnia and Cook (1999) measured the slug length in a $50 \mathrm{~mm}$ diameter pipe having $+5^{\circ}$ by adopting the correlation of Barnea and Taitel (1993). Kadri et al. (2009) studied the dynamics of slugs by introducing a growth model. Average slug length was calculated using the proposed model and results were compared with existing predictions. A decrease in slug length was observed by increasing liquid velocity. The influence of the inlet pressure on the slug length was investigated by Kadri et al. (2010) in nearly horizontal pipelines. He showed that the length of the slug can be reduced significantly by increasing the inlet gas pressure.

\section{Experimental Facility}

Figure 1 depicts a schematic diagram of the experimental apparatus used for this study. The flow loop consists of a $6 \mathrm{~m}$ long horizontal acrylic pipe having internal diameter $74 \mathrm{~mm}$. A centrifugal pump of maximum flow rate $500 \mathrm{~L} / \mathrm{m}$ with inverter to remotely control the flow rate is used to circulate water in the closed loop with digital frequency regulator in order to control the flow rate. A mass flow meter is installed to measure the liquid flow rate. The inlet of the two-phases is designed to be T-shaped, with the gas phase entering horizontally along the acrylic pipe. The air injection setup consists of an air compressor with maximum working pressure 8 bar and an air mass flow meter to measure the inlet flow rate. The acrylic pipe is kept a little inclined with an elevation of about 1.16 degree. The complete system is controlled through a USB Signal Acquisition and Control (USAC) system.

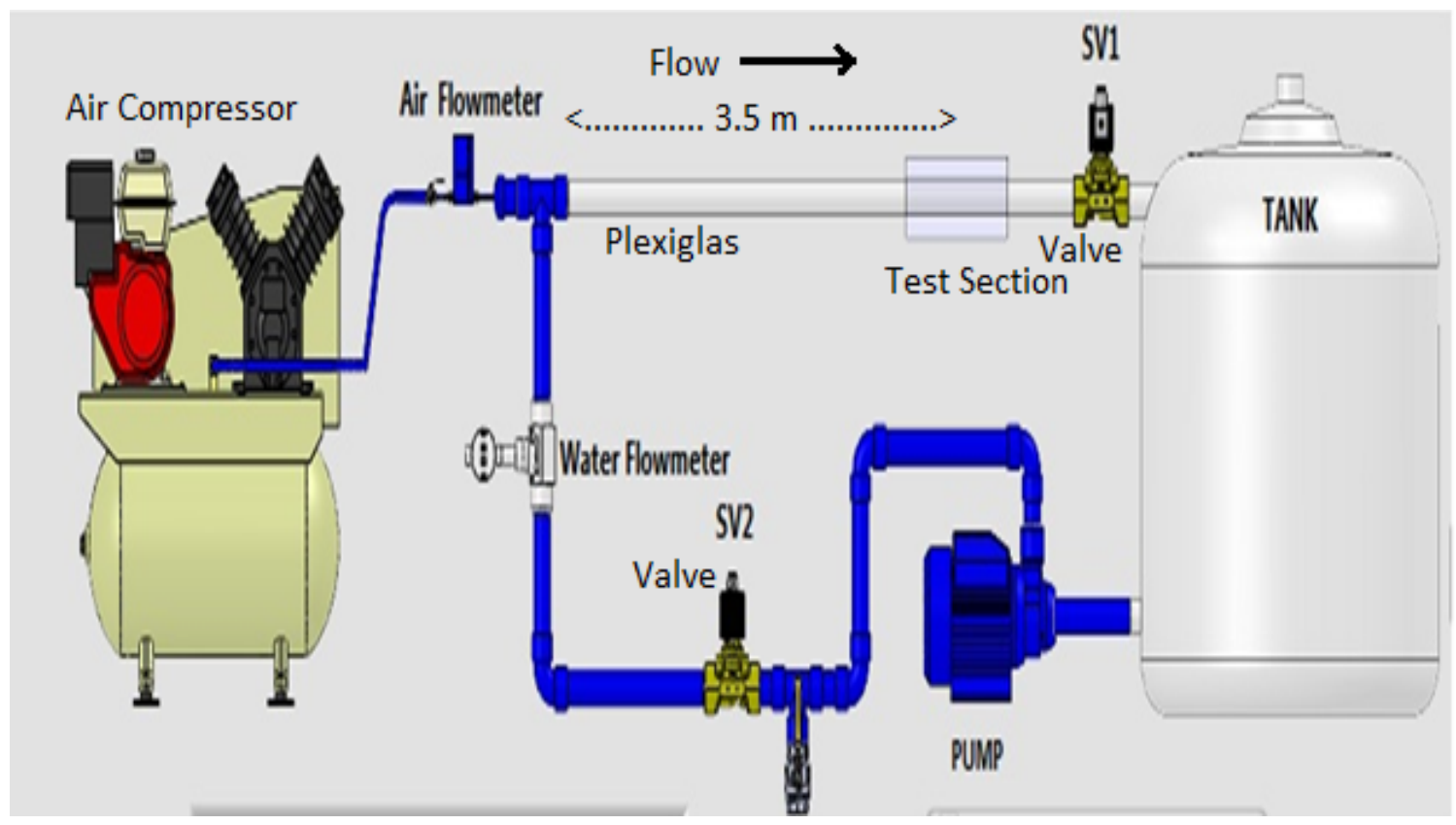

Figure 1. Slug flow experimental facility 


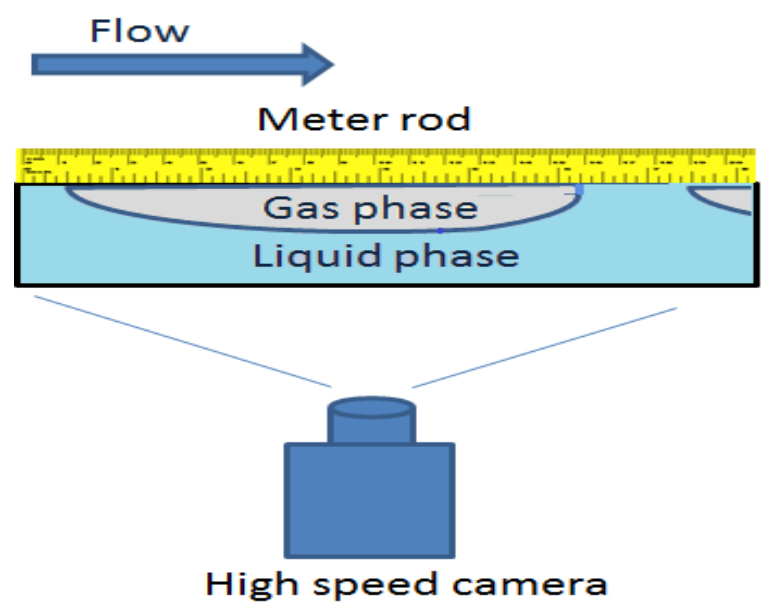

Figure 2. Experimental setup to measure the slug frequency and the bubble length

\section{Measurement Technique}

Two different non-invasive approaches were utilized to study the dynamics of terrain slugging mechanism in nearly horizontal pipeline.

\subsection{Frequency Measurement using High Speed Camera}

Figure 2 shows the experimental setup to measure the slug frequency and bubble length. Slug flow was generated at different flow conditions and the slug frequency and bubble length were measured. A high speed camera (Phantom V7.3) was used to capture the images of the moving slugs in the Plexiglas/acrylic pipe instead of using an invasive probe. The test point was located $4 \mathrm{~m}$ away from the inlet of the mixing zone. The sample rate and exposure of the camera was adjusted, to be 40 frames per second and $1000 \mu$ s respectively, so that the displacement or deformation imposed by the fluid could be seen and recorded. A meter scale was installed in order to calculate the length and the displacement of the moving slug. Several frames of a slug flow are shown in Figure 3.

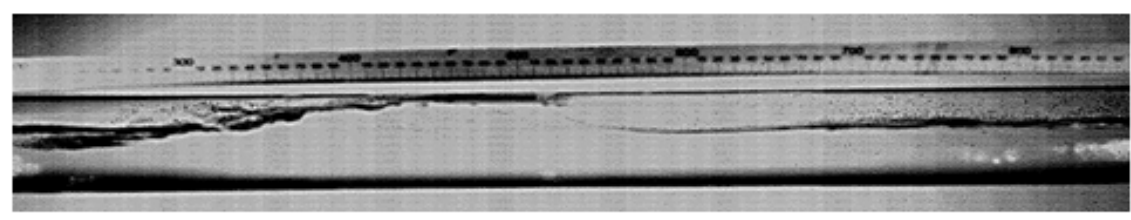

00:57:20.798980

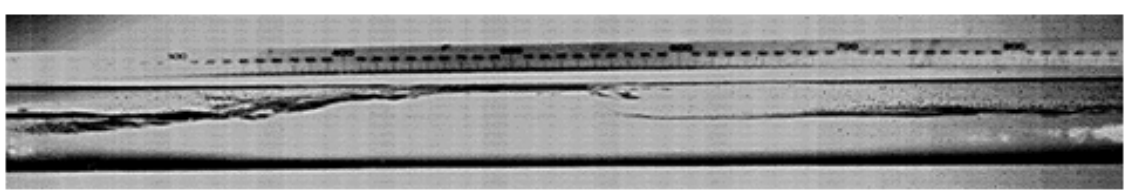

00:57:20.823980

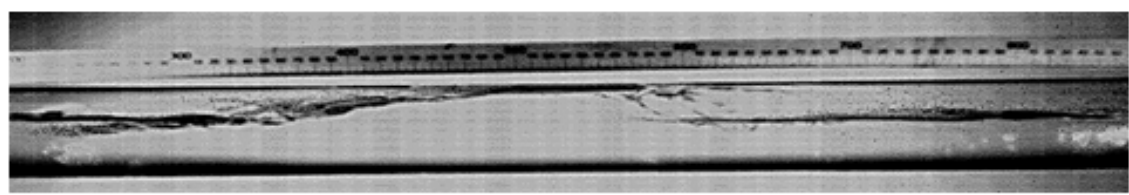

00:57:20.848 980

Figure 3. Sequential images of moving slug in pipe with time interval of $25000 \mu \mathrm{s}$ where the real time of each image is shown underneath 


\subsection{Instantaneous Velocity Measurement Using PIV-LIF Technique}

Figure 4 shows the schematics of the PIV-LIF experimental setup. The liquid phase was seeded with particles with a mean diameter of $20 \mu \mathrm{m}$. These particles were coated with the fluorophore Rhodamine-B, which when illuminated by the green laser light scatters orange light at a wavelength between $555-585 \mathrm{~nm}$. This scattered light is the laser induced fluorescence. PIV can then be applied on the fluorescent particles. The gas phase was seeded with Titanium Dioxide (TiO2) tracer particles using a powder seeding generator. These non-fluorescing $\mathrm{TiO} 2$ particles scatter light at the same wavelength as the laser (Mie scattering). The laser was a double pulsed $\mathrm{Nd}$ :YAG laser capable of $500 \mathrm{~mJ} / 5 \mathrm{~ns}$ pulsing at a frequency of $15 \mathrm{~Hz}$. To differentiate the signals from both phases, two CCD cameras with a resolution of $1344 \times 1024$ pixels were equipped with optical filters. Camera "A" was equipped with a longpass filter with a cut off wavelength at $570 \mathrm{~nm}$ and was used to capture the scattering from the fluorescent particles from the liquid phase. This longpass filter effectively removed all the signal from the gas phase since its emission is only at $532 \mathrm{~nm}$. The gas phase camera "B" was fitted with a band pass filter centred at $532 \mathrm{~nm}$ with a full width at half maximum of $10 \mathrm{~nm}$. This filter effectively eliminated the signal from the fluorescence of the liquid particle.

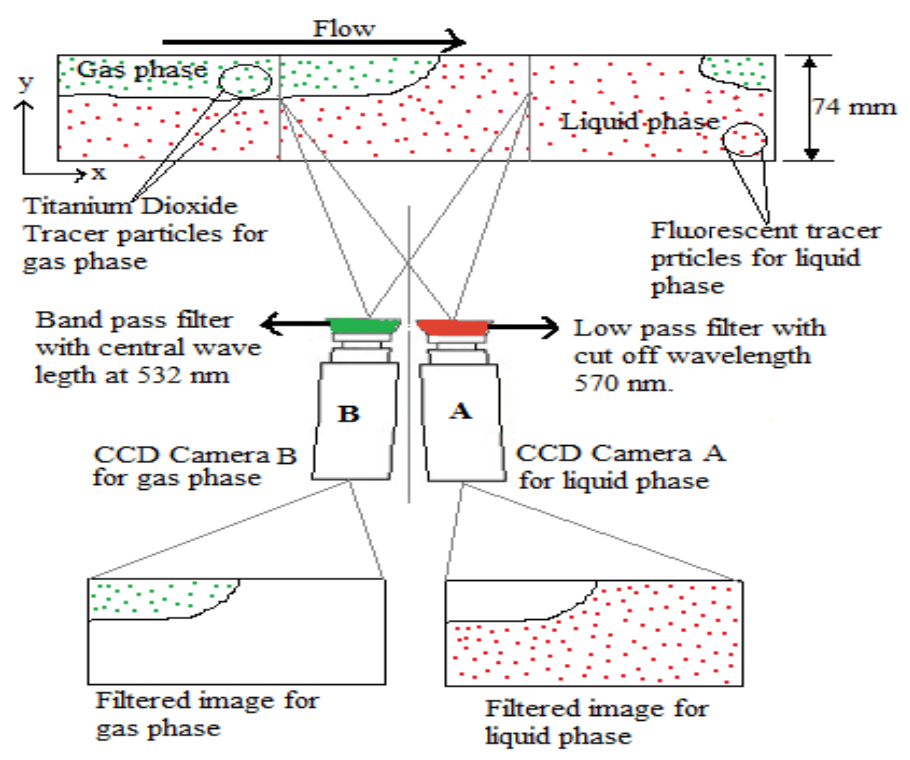

Figure 4. Experimental setup of PIV-LIF technique

\section{Results and Discussion}

\subsection{Effects of Superficial Velocities on Slug Frequency and Bubble Length}

The effect of liquid and gas superficial velocity on the slug frequency and the bubble length were assessed. It was noticed that by increasing the gas superficial velocity (Vsg) the frequency of slugs decreases due the higher ratio of gas to liquid, while keeping the liquid superficial velocity (Vsl) the same, as shown in Figure 5. Also, by increasing the liquid velocity the slug frequency increases as can be expected, the results are in agreement with Hubbard (1965). Moreover, the effects of superficial liquid velocities on the slug length were also studied. It was found that the slug length decreased when the superficial liquid velocity increases. This is because of the higher ratio of liquid to gas as illustrated by Figure 6 . 


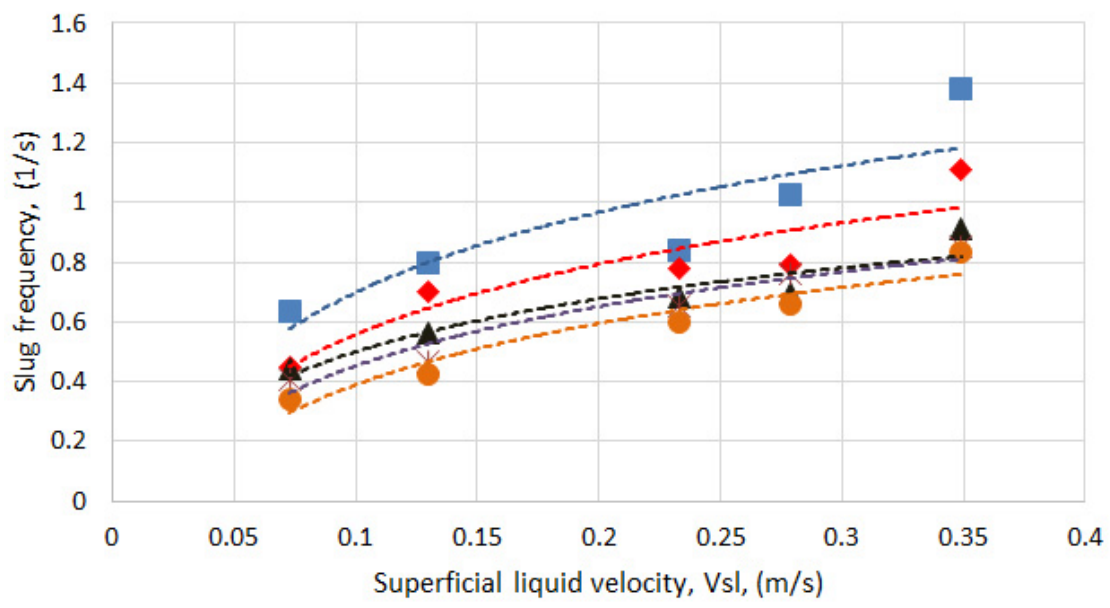

nsg=0.047 m/s $\bullet \mathrm{Vsg}=0.116 \mathrm{~m} / \mathrm{s} \Delta \mathrm{Vsg}=0.233 \mathrm{~m} / \mathrm{s} * \mathrm{Vsg}=0.349 \mathrm{~m} / \mathrm{s} \quad \mathrm{Vsg}=0.465 \mathrm{~m} / \mathrm{s}$

Figure 5. Slug frequency profile at various liquid and gas superficial velocities

On the other hand, the slug length increased with an increase in the gas superficial velocity for the same liquid superficial velocity. Also, for high liquid flow rates, it was noticed that the slug length increased slightly up to a maximum value before decreasing slightly with a further increase in the superficial gas velocity, Figure 7 . The results are in agreement with Gregory and Scott (1969) and Cai et al. (1999).
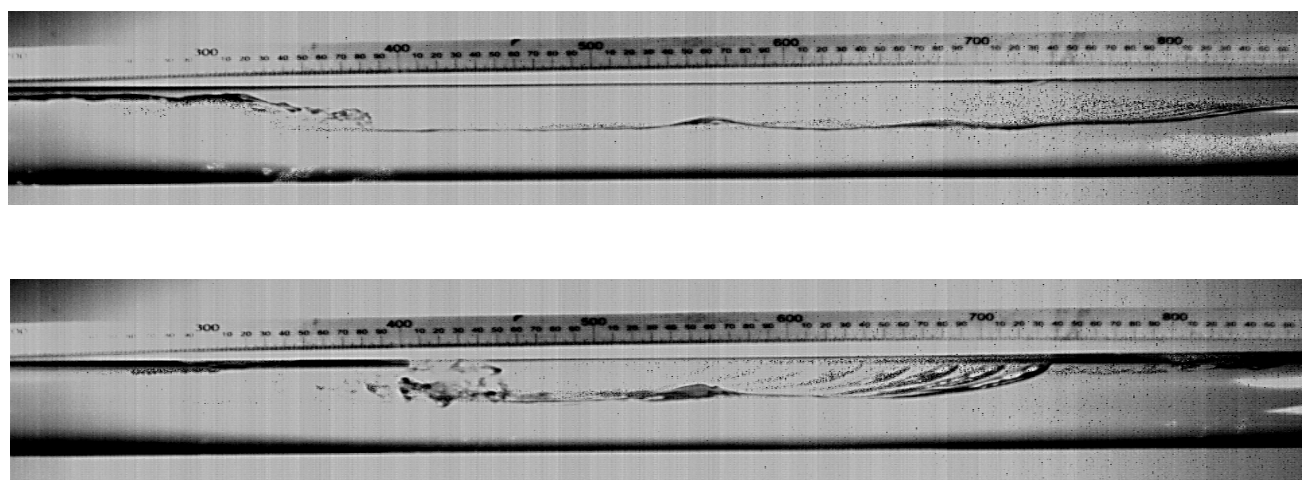

Figure 6. For a superficial gas velocity of $0.116 \mathrm{~m} / \mathrm{s}$, the length of a bubble in a unit slug is decreased significantly by increasing the liquid superficial velocity from 0.073 to $0.349 \mathrm{~m} / \mathrm{s}$

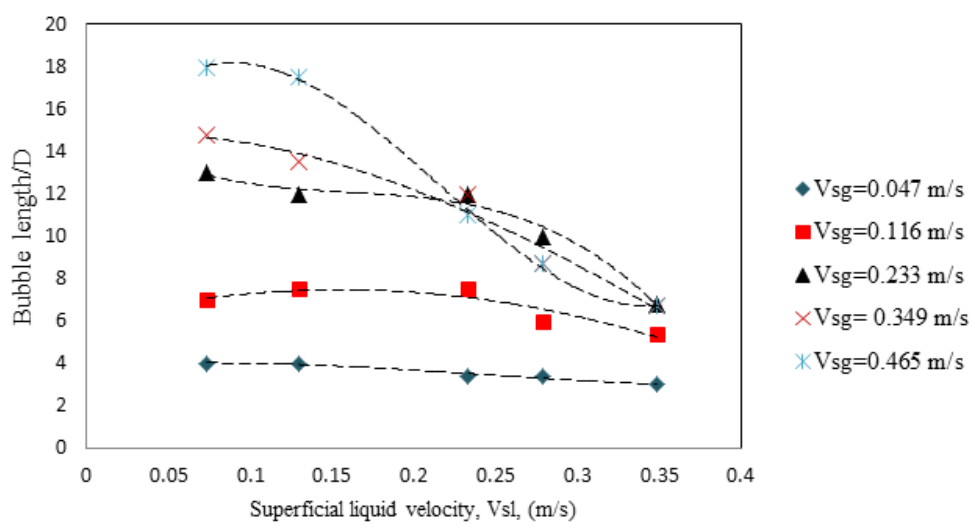

Figure 7. Effect of superficial liquid and gas velocities on the length of the bubble in unit slug where the length of the bubbles is normalised by the pipe diameter (D) 
Further, a comparison of the experimental and predicted slug frequency is show in figure 8. Two models for predicting slug frequency are considered to compare the results. The first model, given by Gregory and Scott (1969), ignores the inclination effects but gives better prediction for horizontal flow conditions with high flow rates. The second model comes from Zabaras (2000). The results are in acceptable agreement. This preliminary study confirms the validity of the test rig.

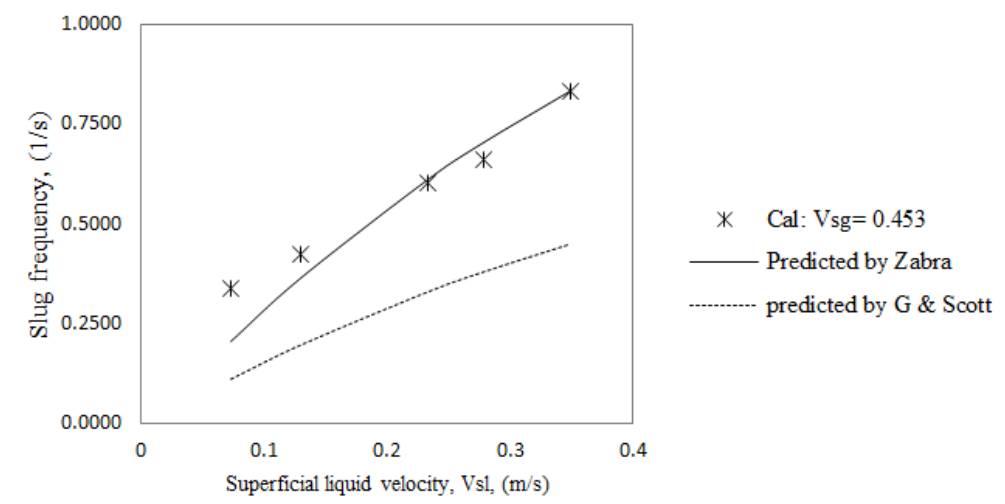

Figure 8. Comparison of a calculated terrain slug frequency and predicted

\subsection{Effects of Superficial Velocities on Slug Liquid Holdup and Average Velocity}

The liquid hold-up in a slug flow depends inversely upon superficial gas velocity in a film region and directly proportional in the liquid slug region. It was observed that the liquid hold-up significantly drops in a liquid film region as increase in the gas superficial velocity, while keeping liquid superficial velocity same, as shown in Figure 9(a-b).
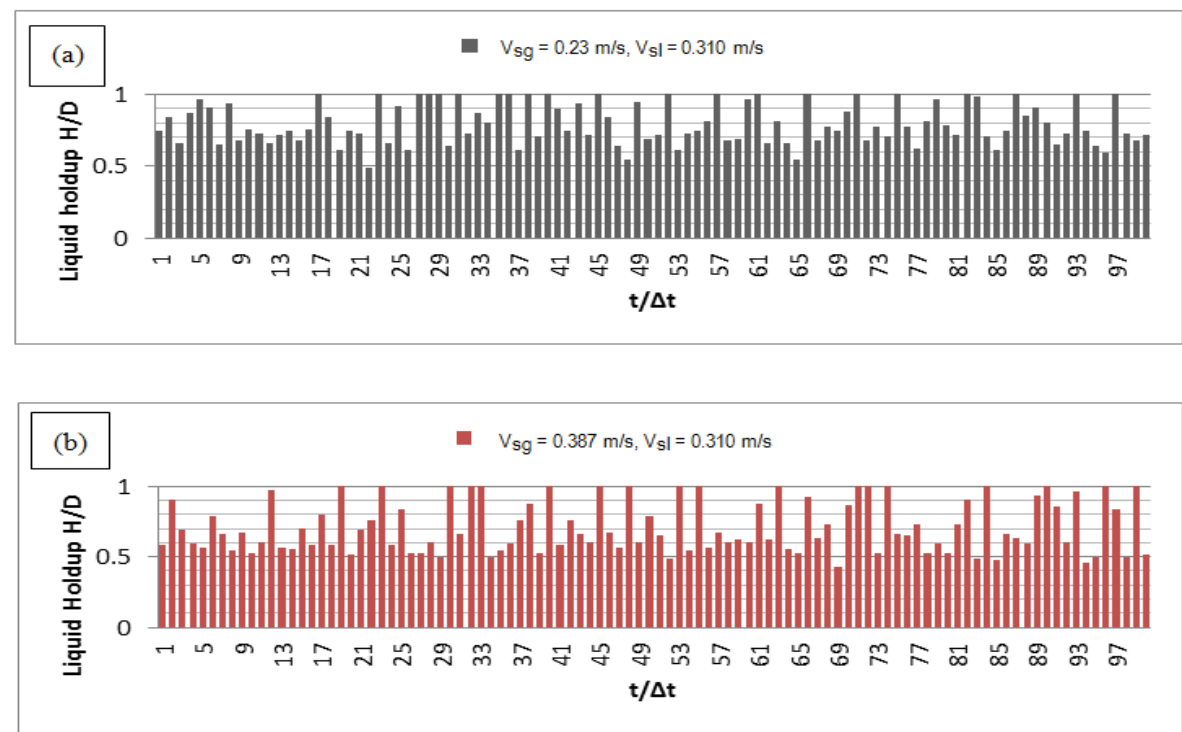

Figure 9. Liquid hold-up in the slug flow at (a) Vsg $=0.23 \mathrm{~m} / \mathrm{s}$, and (b) $\mathrm{Vsg}=0.387 \mathrm{~m} / \mathrm{s}$ keeping liquid superficial velocity same at $\mathrm{Vsl}=0.310 \mathrm{~m} / \mathrm{s}$

By measuring simultaneous velocity of liquid and gas phases in a film region, it was observed that the gas phase remains the dominant over the liquid film. The gas phases travels at a rate double than the liquid film, as shown in Figure 10. This figure shows the axial and the radial velocity profiles of liquid and gas phases in a film region. Moreover, the increase in the gas axial velocity was observed by increasing gas superficial velocity. On the other hand the gas proportion increases in a unit slug that stretched the liquid film resulting in a liquid hold-up drop. Also the variation in the radial velocity component was observed in the gas phase but it remains unchanged in the liquid film. 


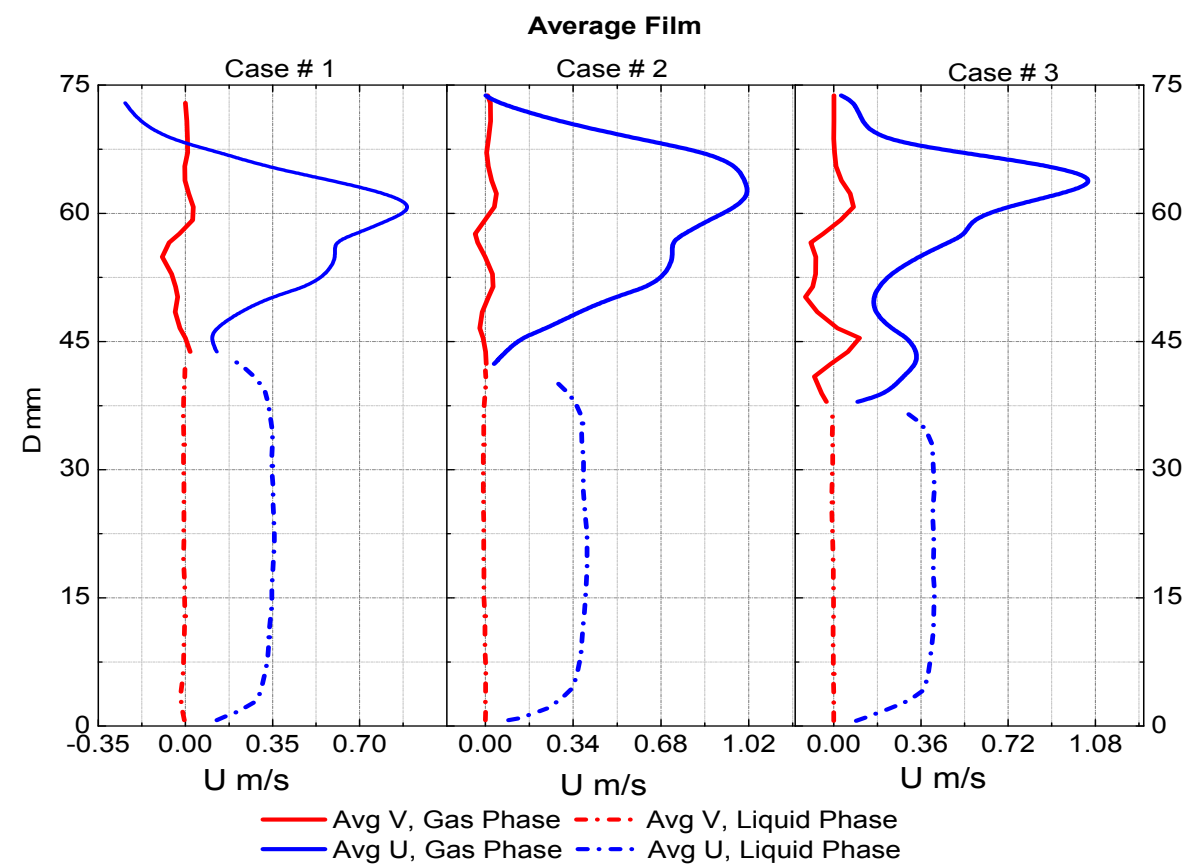

Figure 10. Mean axial and the radial velocity profiles of the liquid and the gas phases in the film region. Where case \# 1,2 and 3 were $(\mathrm{Vsl}=0.310 \mathrm{~m} / \mathrm{s}, \mathrm{Vsg}=0.23 \mathrm{~m} / \mathrm{s}),(\mathrm{Vsl}=0.310 \mathrm{~m} / \mathrm{s}, \mathrm{Vsg}=0.310 \mathrm{~m} / \mathrm{s})$ and $(\mathrm{Vsl}=0.310$ $\mathrm{m} / \mathrm{s}, \mathrm{Vsg}=0.387 \mathrm{~m} / \mathrm{s}$ ) respectively

\section{Conclusion}

In this study, an experimental investigation of slug frequency and slug length was carried out in a 74-mm I.D., 6-m long Plexiglas pipe with inclination of $1.16^{\circ}$. The working fluids were water and air. A high speed camera was used to calculate the slug frequency by taking still pictures with known separation of time and displacement. It was observed that the slug frequency increased with increasing the superficial liquid velocity under all conditions. Also, it was seen that for the same superficial liquid velocity the slug frequency decreased with increasing the superficial gas velocities. The obtained slug frequency profiles were further compared with the existing empirical correlations in the literature and an acceptable agreement was found. The length of the bubble section in the unit slug was measured under different flow conditions. It was seen that the bubble length decreased with increasing the superficial liquid velocity under all conditions. Also for lower liquid flow rates, the bubble length increased with the increase in the superficial gas velocity. But for high liquid flow rates, the bubble length increased slightly to a maximum and then decreased by increasing the superficial gas velocity. All results were in acceptable agreements with the existing results. A significant drop in the liquid hold-up was observed in the film region by increasing gas superficial velocities. Further PIV-LIF technique was used to measure the instantaneous velocity profiles of the liquid and gas phases in the film region of the slug flow. The gas phases remained dominant in the film region moving at a rate double than the liquid phase. Increase in the gas axial velocity was observed with increase in gas superficial velocity but on the other hand the effect of inlet conditions was not significant on the velocity inside liquid film.

\section{Acknowledgments}

We are thankful for the financial support from the YUTP, ITPSB and URIF internal funding from Universiti Teknologi PETRONAS.

\section{References}

Barnea, D., \& Taitel, Y. (1993). A model for slug length distribution in gas-liquid slug flow. International Journal of Multiphase Flow, 19, 829-838. http://dx.doi.org/10.1016/0301-9322(93)90046-W

Cai, J. Y., Wang, H. W., Hong, T., \& Jepson, W. P. (1999). Slug frequency and length inclined large diameter multiphase pipeline. In: Proceedings of 4th International Symposium, Multiphase Flow and Heat Transfer, Xi' an China, 22-24 August, 195-202.

Cook, M., \& Behnia, M. (2000). Slug length prediction in near horizontal gas liquid intermittent flow. Chemical 
Engineering Science, 55, 2009-2018. http://dx.doi.org/10.1016/S0009-2509(99)00485-6

Fagundes, N. J. R., Fabre, J., \& Peresson, L. (1999). Shape of long bubbles in horizontal slug flow. International Journal of Multiphase Flow, 25, 1129-1160. http://dx.doi.org/10.1016/S0301-9322(99)00041-5

Gregory, G., \& Scott, D. S. (1969). Correlation of liquid slug velocity and frequency in horizontal co-current slug flow. AIChE J., 15, 933-935.

Hubbard, M. (1965). An analysis of horizontal gas-liquid slug flow. PhD dissertation, University of Houston, TX.

Kadri, U., Henkes, R. A. W. M., Mudde, R. F., \& Oliemans, R. V. A. (2011). Effect of gas pulsation on long slugs in horizontal gas-liquid pipe flow," Int $J$ Multiphase Flow, 37, 1120-1128. http://dx.doi.org/10.1016/j.ijmultiphaseflow.2011.07.003

Kadri, U., Mudde, R. F., \& Oliemans, R. V. A. (2010). Influence of the operation pressure on slug length in near horizontal gas-liquid pipe flow. International Journal of Multiphase Flow, 36, 423-431. http://dx.doi.org/10.1016/j.ijmultiphaseflow.2009.12.006

Kadri, U., Zoeteweij, M. L., Mudde, R. F., \& Oliemans, R. V. A. (2009). A growth model for dynamic slugs in gas-liquid horizontal pipes. International Journal of Multiphase Flow, 35, 439-449. http://dx.doi.org/10.1016/j.ijmultiphaseflow.2009.02.003

Paglianti, A., Goina, M., \& Soldati, A. (1996). Characterization of sub regimes in two-phase slug flow. Int. J. Multiphase Flow, 22(4), 783-796.

Sanchez, S. F., Toledo V. M., \& Hernandez, G. A. (1998). Slug flow momentum transfer analysis to determine the forces acting on a $90^{\circ}$ elbow in a horizontal pipe. In 3rd International Conference on Multiphase Flow, Lyon, France.

Taitel, Y. (1987). Effect of gas expansion on slug length in long pipelines. International Journal of Multiphase Flow, 13(5), 629-637. http://dx.doi.org/10.1016/0301-9322(87)90040-1

Tay, B. L., \& Thorpe, R. B. (2002). Forces on pipe bends due to slug flow. In: Proceedings of 3rd North American Multiphase Technology Conference, Banff, 281-300.

Tay, B. L., \& Thorpe, R. B. (2004). Effect of liquid physical properties on the forces acting on a pipe bend in gas-liquid slug flow. Chem Eng Res Des, 82(A3), 344-356. http://dx.doi.org/10.1205/026387604322870453

Zabaras, G. J. (2000). Prediction of slug frequency for Gas-liquid flows. SPE Journal, 5(3), 252-258.

\section{Copyrights}

Copyright for this article is retained by the author(s), with first publication rights granted to the journal.

This is an open-access article distributed under the terms and conditions of the Creative Commons Attribution license (http://creativecommons.org/licenses/by/3.0/). 